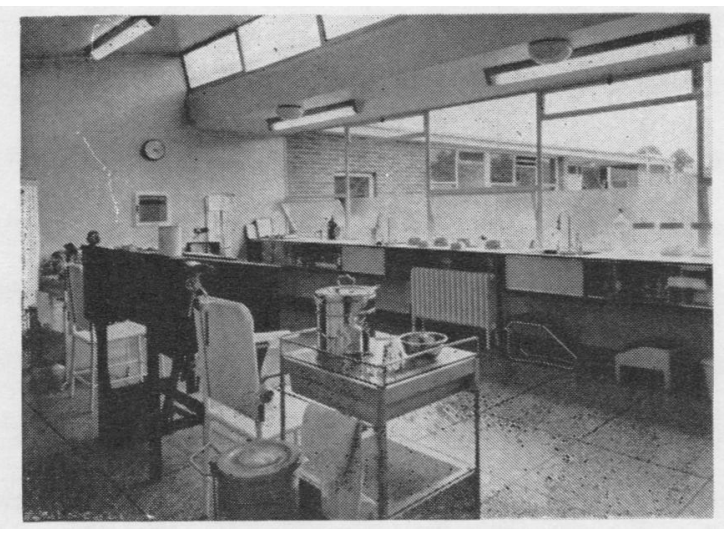

\section{Medical Planning at Aldenham Works}

Building a completely new works affords a rare opportunity for an industrial medical officer. Not only is he concerned with the plans for his own kingdom, the works surgery, but he finds himself consulted at all stages so that the final human environment may be a healthy and agreeable place of work.

The recently opened Aldenham Works, where the buses belonging to the London Transport Executive are overhauled and refitted, provided such an opportunity for the Executive's medical department, and particularly for Dr. A. W. Gilks, divisional medical officer of London Transport. And now that the works is in full production the medical supervision of environmental working conditions and of the methods and materials is as much a part of the doctor's task there as is that of his more obviously medical duties in the surgery. However, at the Aldenham Works occupational hazards are comparatively few. The paint sprayers are kept under regular observation. For them specially designed spraying booths ensure proper ventilation, and special clothing and masks are worn. Also, the manufacturers of the paint used in spraying cooperated with the management in trying to eliminate as far as possible the noxious elements in the paint itself. All the paint sprayers are volunteers in good health, who undergo a full medical examination, including a blood count, on starting work. The blood count is repeated every six months.

The works surgery was designed by the architect in collaboration with the Chief Medical Officer, and is in charge of a State Registered nurse assisted by a State enrolled assistant nurse. The nurses treat accidents and illness occurring at work and continue treatments initiated by general practitioners, so that employees' time off work is kept to a minimum. The doctor also visits Aldenham at least once a week, but patients requiring specialized investigations are referred to the bigger medical centre at the Chiswick works. By a special arrangement with the Surgical Director of the Accident Unit of the Royal National Orthopaedic Hospital, serious accident cases are taken there by ambulance immediately, and later any necessary treatment or supervision is carried out at the works surgery in consultation with the hospital surgeon. This arrangement secures the best immediate care and afterwards reduces time off work.

Neither the design of the works surgery at Aldenham nor the function of the medical officer there is unique, but both are inheritors of long and successful cooperation between management and medical department.

G. L.

\section{British Occupational Hygiene Society and Ergonomics Research Society}

\section{TURNER}

A joint meeting for the presentation of scientific communications was held by the British Occupational Hygiene Society and the Ergonomics Research Society at the London School of Hygiene and Tropical Medicine on June 29,1956 . The meeting was attended by about 80 members. At the morning session the chair was taken by Dr. C. G. Warner.

In a paper on " Energy Expenditure and the Grading of Work in a Modern Factory ", J. R. Brown and G. P. Crowden, of the London School of Hygiene, described the results of a survey of 23 different tasks performed by both men and women in a light engineering factory. A total of 102 individual tests were made in which the metabolic rate of the worker was measured and the severity of the task independently assessed on a workgrade scale by one of H.M. medical inspectors of factories. Comparisons were drawn between the scale used in this study and others proposed by the Royal Society (1919), the British Medical Association (1950), and Christensen (1953). A film illustrating the survey was also shown.

In a preliminary report on " Exposure to Chloroform in Industry ", P. J. R. Challen and D. E. Hickish, with Joan Bedford, described an investigation of a process in which chloroform was incorporated in the manufacture of medicinal lozenges and where a problem had arisen after the mechanization of an existing process. Air samples indicated that the operators had been exposed to concentrations of chloroform in excess of the maximum allowable concentration. On clinical examination employees complained of symptoms which were consistent with exposure to chloroform. The results of liver function tests were within normal limits.

F. W. Mead, R. C. Browne, and A. F. Burstall, of King's College, Newcastle-upon-Tyne, discussed the " Oxides of Carbon in a Diesel Engine Exhaust and the Fuel-air Ratio in the Cylinders ". They described the results of experiments in which a well-known type of transport diesel engine was run with measured fuel and air consumption, and the percentages by volume of carbon monoxide and dioxide in the exhaust were related to the fuel-air ratio in the cylinders. Increasing the fuel-air ratio from 0.0123 to 0.44 (the makers' maximum value) linearly increased the percentage by volume of carbon dioxide in the exhaust from 2.0 to 9.0 and the power output from zero to $25 \cdot 2$ b.h.p. At the same time the carbon monoxide in the exhaust fell from 0.08 to $0.05 \%$ 
by volume. Further increase in the fuel-air ratio to 0.0716 caused the exhaust to smoke and the carbon monoxide proportion to rise to $1 \cdot 2 \%$, whereas the carbon dioxide percentage fell slightly. Under these conditions the engine developed $16 \%$ more power than it did at the makers' maximum suggested fuel-air ratio.

"The Occupational Hazards of Agriculture" were the subject of a paper by E. F. Edson, of Fisons Pest Control Ltd. Information was presented on the size of the agricultural industry in England and Wales. Typical farm operations were illustrated by slides, emphasizing factors such as isolation, lack of direct supervision, and other risky circumstances inevitable in farm work. An analysis of the annual 130 fatal accidents and 20,000 accidents causing loss of time in farming was given and reference made to the basic healthiness of the farming community.

After lunch the chair was taken by Dr. O. G. Edholm. J. E. Cotes, F. Meade and M. E. Wise, of the M.R.C. Pneumoconiosis Research Unit, described an analysis of "Treadmill Walking as a Form of Exercise". V. Timbrell, also of the Pneumoconiosis Research Unit, then presented a communication on "Some Physical Aspects of Ballistocardiography". Some aspects of the theory of the separated-table ballistocardiograph were considered. The table moves under the action of the pulsating force produced by the motion of the blood in the subject lying on it. In order that the ballistocardiogram, which is the record of the displacement of the table with time, may represent the impressed force, the ballistocardiograph must possess certain characteristics. The characteristics are those of a simple vibrating system with a high natural frequency and a damping factor of about $\mathbf{0} \cdot 5$. The practical ballistocardiograph must be regarded as a complex system; for example, the frame may not be sufficiently rigid and may vibrate. The characteristics must be determined experimentally and the system modified until the desirable characteristics are obtained. To enable cardiac output to be estimated from the ballistocardiogram, the sensitivity of the system is set to some standard value. For this purpose a mechanical oscillation is employed which applies a sinusoidal force of constant amplitude at a frequency of $2 \frac{3}{4}$ cycles per second to the total loaded with dead weight. Such oscillation serves as a subject of constant cardiac output.

"Age and Learning; Theory and Needed Research" was the title of a paper by A. T. Welford, of the Nuffield Foundation Research Unit into Problems of Ageing, Cambridge.

After an interval for tea Dr. T. Bedford took the chair. K. J. Collins, of the M.R.C. Climate and Working Efficiency Research Unit, discussed the problem of "The Corrosion of Metal by Palmar Sweat". A large number of manufacturing, assembling, and packing operations involve handling, with the concomitant risk of contamination by palmar sweat. Sweat residues are particularly troublesome in the case of highly finished metal surfaces and subsequent corrosion is rapid. Some individuals may handle degreased metal parts without causing tarnishing, while others cause considerable corrosion. There is variation in this effect, both from person to person and with the same person at different times. The results of preliminary investigations suggested that the quantity of sweat produced is an important factor in determining the extent of corrosion. However, differences in the amount of corrosion were not always related to individual rates of sweating, but might also be attributed to variations in the composition of palmar sweat. An estimate of the corrosive effect of a number of sweat constituents was obtained by placing drops of solutions containing known physiological amounts of solute on polished steel. Severe rusting was caused by concentrations of inorganic salts similar to those reported by Lobitz and Osterberg (1947) in palmar sweat. Other sweat components, particularly nitrogenous compounds such as urea, were also active in solution. Experiments with artificial sweat solutions indicated that corrosion was enhanced at acid $p H$ as compared with neutral or alkaline solution. Special sweat-removing measures are not commonly used, although sweat residues can be removed by aqueous alkaline or emulsion cleaners. Contamination may be prevented by the use of rubber gloves or forceps, but such expedients are frequently unsuitable. Certain barrier creams have been tested and appear to be effective, to some extent, in reducing corrosion although, apparently, only in those cases where palmar sweating is slight.

An abstract of a paper entitled " The Absorption and Elimination of Isotopes of Inert Gases, with Special Reference to Krypton ", was read on behalf of J. E. S. Bradley. Classical methods for the estimation of body fat in man are indirect, laborious, and of low precision, as has been shown by the work of Keyes. Moreover, they are difficult to validate precisely in those conditions where the results are of most interest. In consequence, several investigators have sought to use substances having a high solubility in fat, in order to obtain a more direct estimate. The work of Loesser with cyclopropane is particularly important in this field. Previous methods were reviewed, and a brief description of the technique developed for use with radioactive isotopes of inert gases, together with some preliminary results, were given. For purely technical reasons krypton had been mainly employed, although xenon would have been preferable from some points of view. Some more general implications arising from the operations of the atomic energy industry were drawn.

The meeting concluded with a general discussion on the problem of " Heat Stress in Industry". The discussion was opened by J. Weiner, who described the results of some observations made by himself and his colleague, A. R. Lind, of the M.R.C. Climate and Working Efficiency Research Unit, followed by a full discussion of this problem of general interest.

\section{REFERENCES}

British Medical Association (1950). Report of the Committee on Nutrition, p. 13.

Christensen, E. H. (1953). In Ergonomics Research Society. Symposium of Fatigue, edited by W. F. Floyd and A. T. Welford, pp. 93-108. H. K. Lewis, London.

Lobitz, W. C., and Osterberg, A. E. (1947). Arch. Derm. Syph., 56,

Royal Society (1919). Food (War) Committee. Report on the Food Requirements of Man and Their Variations According to Age,
Sex, Size, and Occupation. Harrison, London. 